\title{
Work Organisations
}

A Critical Introduction 


\title{
Work Organisations A Critical Introduction
}

\section{Second Edition}

\author{
Paul Thompson \\ and \\ David McHugh
}


(C) Paul Thompson and David McHugh 1990, 1995

All rights reserved. No reproduction, copy or transmission of this publication may be made without written permission.

No paragraph of this publication may be reproduced, copied or transmitted save with written permission or in accordance with the provisions of the Copyright, Designs and Patents Act 1988, or under the terms of any licence permitting limited copying issued by the Copyright Licensing Agency, 90 Tottenham Court Road, London W1P 9HE.

Any person who does any unauthorised act in relation to this publication may be liable to criminal prosecution and civil claims for damages.

First published 1995 by

MACMILLAN PRESS LTD

Houndmills, Basingstoke, Hampshire RG21 6XS

and London

Companies and representatives

throughout the world

ISBN 978-0-333-64161-3

ISBN 978-1-349-24223-8 (eBook)

DOI 10.1007/978-1-349-24223-8

A catalogue record for this book is available from the British Library.

$\begin{array}{llllllllll}10 & 9 & 8 & 7 & 6 & 5 & 4 & 3 & 2 & 1\end{array}$

$\begin{array}{llllllllll}04 & 03 & 02 & 01 & 00 & 99 & 98 & 97 & 96 & 95\end{array}$

Copy-edited and typeset by Povey-Edmondson

Okehampton and Rochdale, England 


\section{Contents}

List of tables and figures

Acknowledgements $\quad$ xi

Introduction xii

\section{PART 1}

1 Studying organisations: an introduction 3

Domain assumptions of mainstream approaches 9

Organisations as goal-seekers 9

In search of the rational-efficient organisation 10

Order and hierarchy 11

Managerialism 12

A science of organisations 13

An evaluation of mainstream perspectives 13

Domain assumptions of a critical approach 17

Reflexivity 17

The embeddedness of organisations 18

Multi-dimensionality $\quad 19$

Dialectics and contradiction $\quad 20$

Social transformation $\quad 21$

2 The emergence of large-scale organisations 23

Organising the new work forms 23

The rise of the factory system 24

Modes of control in the transition to bureaucratic organisation $\quad 26$

Decay and decline of traditional controls 29

Classical theories and the bureaucratisation of production 32

Taylorism and systematic management $\quad 32$ 
Weber and administrative theories of management

Social science and industry: a courtship 43

Enter the human factor 44

Hawthorne and beyond $\quad 47$

Consolidating human relations $\quad 51$

Conclusion and evaluation $\quad 53$

Back to the future? 53

Beyond the American model 55

3 Organisations and environments $\quad 59$

Adaptation theories 61

Open systems $\quad 62$

Contingency theory 66

Selection theories: the population ecology approach 69

Critique and alternative 71

$\begin{array}{ll}\text { The state and the political environment } & 79\end{array}$

Theorising the state $\quad 80$

Dimensions of state economic activity $\quad 82$

$\begin{array}{ll}\text { Restructuring the public sector } & 87\end{array}$

Retheorising the state: a reflection 91

Local and the global in new business environments 94

Institutional theories $\quad 94$

$\begin{array}{lr}\text { Globalisation } & 97\end{array}$

$\begin{array}{ll}\text { Conclusion } & 100\end{array}$

4 Management and control 103

The nature of management 105

Managers as leaders and decision-makers 107

Management practices: a new realism? 109

Control

Radical perspectives $\quad 112$

Management strategies $\quad 115$

Questioning the idea of control strategies $\quad 119$

Bringing the threads together: management as a labour process

5 Power 132

Power in mainstream theory $\quad 133$

A critical evaluation $\quad 136$

Foucault and disciplinary power 139

Applications to organisations $\quad 141$

Critique 143

Gender, sexuality and power 146

$\begin{array}{ll}\text { Gendering organisational analysis } & 147\end{array}$ 
Enter sexuality $\quad 150$

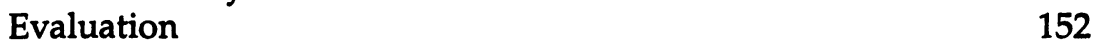

6 Organisational design: beyond bureaucracy? 155

Definitions and issues $\quad 155$

Bureaucratic work organisation reassessed 157

Bureaucracy: the internal critique 159

Alternative designs in a bureaucratic framework $\quad 160$

Contemporary developments: the post-bureaucratic organisation? 165

A paradigm shift? 165

Japan as design model 167

Firms, markets and hierarchies $\quad 169$

Redrawing the firm and its boundaries 173

Control and commitment in the labour process 177

Restructuring the corporation $\quad 179$

Evaluating the changes 181

Firms and markets $\quad 181$

The labour process 186

Corporate structures 191

Conclusion: in defence of bureaucracy? 194

7 Re-inventing organisation man? 198

Product and perspective 201

The corporate culture merchants 201

HRM and the management of culture 205

Critics and questions 207

Questioning the novelty 207

Questioning the evidence 209

Questioning the conception 210

Culture: commitment or control? 212

The limits to culture 215

$\begin{array}{ll}\text { Conclusion } & 220\end{array}$

\section{PART 2}

8 Issues in organisational behaviour 223

Defining the 'subjective factor' 223

Organisational psychology: the mainstream agenda 226

Perception: learning what to see 228

Learning and socialisation: seeing what to do 234

The attitude problem 240

Personality: masks for tasks 245

Motivation: the drive for satisfaction 251

Conclusion: the limits of social and organisational psychology 258 
9 Regulating organisational behaviour?

Organisational psychology and organisational behaviour:

technologies of regulation?

The roles of organisational psychologists 264

The authority of the group

Stress: the force to adapt

The power to communicate

Leadership: might or myth?

Conclusion

10 Mobilising commitment

The 'kick in the ass' life cycle

Motivation as a problematic concept

Control and integration

Control and self-concepts

Engaging the intellect

Learning to change

Committed to work?

Human resources - strategy into surveillance

Conclusion

11 Identity work

Explanations of identity

Redefining the agenda

Organisations and identities

Putting the pressure on

Role control

Role stress

Stress control?

Responses to pressures on identity

Individual responses

Group responses

Management: from response to regulation

Conclusion

\section{PART 3}

12 Theorising organisations

The story so far

Resources for orthodoxy

Weber, bureaucracy and rationality

Durkheim, human relations and social needs

Systems theory 
$\begin{array}{ll}\text { Critical alternatives } & 369\end{array}$

Social action theory $\quad 369$

$\begin{array}{ll}\text { Radical structuralism } & 371\end{array}$

Marx and labour process theory $\quad 371$

Radical Weberianism $\quad 376$

The Post-modern challenge to rationality $\quad 378$

$\begin{array}{ll}\text { Critical social psychologies } & 383\end{array}$

$\begin{array}{ll}\text { Social action } & 385\end{array}$

Marxism, psychology and beyond 386

$\begin{array}{ll}\text { New thoughts? } & 388\end{array}$

$\begin{array}{ll}\text { Theory, knowledge and practice } & 390\end{array}$

Paradigm diversity or closure? $\quad 390$

Management and theory $\quad 392$

Learning from past and present $\quad 394$

$\begin{array}{ll}A \text { guide to key reading } & 398\end{array}$

$\begin{array}{ll}\text { Bibliography } & 404\end{array}$

Name index 444

$\begin{array}{ll}\text { Subject index } & 453\end{array}$ 


\section{List of tables and figures}

\section{Tables}

4.1 Managerial functions

4.2 Institutionalisation of management functions 126

6.1 'Henry's table'

10.1 Teamworking at ISE

\section{Figures}

6.1 The flexible specialisation hypothesis $\quad 170$

6.2 Model of the flexible firm 174

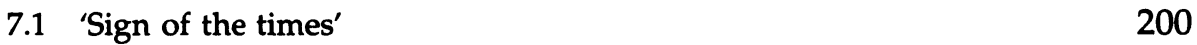

$\begin{array}{lll}8.1 & \text { The perceptual process } & 230\end{array}$

8.2 Context, content and conduct 250

9.1 'Psychological warfare 263

9.2 Group development process $\quad 270$

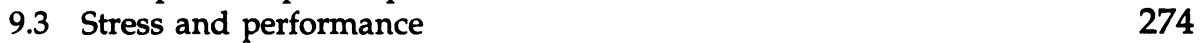

9.4 Context and the communication process 283

$\begin{array}{ll}9.5 \text { Communication openness } & 284\end{array}$

10.1 Management control of motivating influences 298

10.2 An integrated control theory model of work motivation 306

10.3 The interrelation of dimensions of experiencing and shaping of work 342 


\section{Acknowledgements}

Re-doing a book should not be as much of a burden as creating it in the first place. But as usual, the project seems to have been around for an interminable time and once again we have to thank our families for their support through long nights and missed deadlines.

Our colleagues old and new, at the University of Central Lancashire and University of Edinburgh, have given sterling support. Chris Warhurst and Carol Jones, in particular have read chapters and offered invariably sound advice. Paul Thompson would particularly like to thank his fellow researchers - Terry Wallace, Jörg Flecker and Denis Nickson - whose work is drawn on in some of the chapters. We also owe particular gratitude to the many users of the book, some of whom have been kind enough to give us feedback along the way and about the plans for a new edition. Chris Smith, Steve Ackroyd, Alan Tuckman, Les Prince, Martin Corbett have been particularly helpful.

At Macmillan, Steve Rutt, who nursed us through the first edition, has done an even more sterling job on this one. Jane Powell has also provided useful support.

PAUL THOMPSON

DAVID McHUGH

The authors and publishers are grateful to the following for permission to use copyright material: Butterworth-Heinemann Ltd for a diagram from Terence Jackson, Organisational Behaviour in International Management (1993). Every effort has been made to contact all the copyright-holders, but if any have been inadvertently omitted the publishers will be pleased to make the necessary arrangement at the earliest opportunity. 


\section{Introduction}

Our aim in writing the first edition of Work Organisations was to provide a critical alternative to the standard, often American, texts that still predominated in the 1980s, and to some of the derivative British versions. That 'standard' tended to combine a narrow and prescriptive orientation to issues of management, structure and organisational design; with a behavioural agenda dealing with issues such as personality and perception, where a focus on the individual appeared to have little relationship to the more 'structural' material.

'Critical' meant that we aimed to balance exposition and evaluation of mainstream writing and research, with an attempt to bring together the large, but often fragmented, body of writings from organisation and management theory, labour process analysis, feminism, industrial sociology and social psychology, where they were radical and relevant to the study of work organisations. Any orientation of this sort by definition had to be interdisciplinary, pluralistic and pragmatic in the sources it draws from for inspiration. The biggest problem was how to link the broadly sociological and more behavioural material. We did not pretend that any form of grand integration was possible. Our aim was to ensure that the discussion in the two main parts of the book were complementary in the kind of analysis used and issues discussed. We felt strongly that organisations are places in which attempts to shape the subjectivity and identity of employees are central to the purposes of management, and that this provided an important bridge and common focus between debates in the different chapters.

We have not shifted any of these aims for the second edition. But we have thought carefully about how successful we have been in achieving them. A second edition also gives an opportunity to reflect on the feedback through reviews, as well as responses from users. These have generally been kind, but we have tried to respond to some of the issues raised. One persistent theme has been that the book was not 'introductory' enough. This is a difficult one, because a satisfying book to write is one that engages with peers as well as students. Anyway, we have tried to make this edition more accessible in a 
number of ways, the most significant of which is to shift the discussion of general theory from the beginning to the end. In its new location, we can be more comprehensive about theory without getting in the way of a more straightforward and less burdensome entry into the issues.

A fresh start also gives an opportunity to be more comprehensive and to introduce materials that were previously neglected. So we have added new sections such as those on communication and leadership. Organisation theory and research, like organisation itself, is very diverse, and textbook writers have to be careful about simply reproducing partial accounts and experiences. We have, therefore, tried to introduce more comparative material that reflects that diversity. The rise of more internationally-orientated debates, such as those on globalisation, is but one example of the remarkably rapid changes in the organisation studies literature that has taken place in the five years since the first edition. The book seeks to reflect those changes and debates. There is now a substantial literature on gender and organisations that simply did not exist in the late 1980s. Most of that focuses on power rather than the conventional division of labour framework. We have, therefore, made issues of power into a separate chapter, reflecting this and the other significant debates arising from the work of Foucault and post-structuralism. Not every area of debate has undergone decisive shift. In chapters dealing with issues such as management and control, and organisation design we have simply tried to update debates and research. Though in the latter case we have substantially re-focused and extended the chapter to enable a more thorough discussion of the question of whether the end of the century is seeing the rise of the 'post-bureaucratic organisation'.

\section{Structure of the book}

Part 1 focuses on the areas traditionally dealt with by organisation theory and more sociological and structural writings. Chapter 1 seeks to explore three main questions: why are we interested in studying organisations? how should they be studied? and what are the general concepts and principles available to do so? These objects are achieved by contrasting the 'domain assumptions' of mainstream and critical approaches. By this we mean some of the basic ways that rival perspectives have looked at organisations and society. At this stage the idea is to keep it fairly simple. We do not look at theory or theories in depth, but at some of the underlying and underpinning assumptions. The more adventurous reader could go to Part 3 and immediately follow that through. But it is not necessary to do that in order to follow the substantive discussions in the chapters in between, where we develop an understanding of theory and research in a more incremental way. 
A great weakness of much organisational writing is the failure to locate analysis in its historical context. Chapter 2 seeks to show how the major characteristics of large-scale organisations in the twentieth century - control, hierarchy and bureaucracy - came into being. We particularly try to identify the origins and developments of the best known, 'classical' theories of organisation, notably Taylorism, Weber and the human relations movement. The focus is firmly on the attendant practices and use by management, both in the periods when the ideas emerged and the legacies left for later eras. Such practices, however, were never universal. At the end of the chapter we introduce a recurrent theme of the book, that different organising logics are embedded in contrasting national and other institutional frameworks. For example, what is defined as management in Britain and North America is not necessarily the model elsewhere.

This point highlights the importance of the environment of work organisations. Yet such environments are often dealt with in a limited way, certainly once markets and technologies have been discussed. Chapter 3 outlines and evaluates the mainstream literature, including contingency theory and population ecology. But we open out the discussion in two ways. First by examining the political environment through the role of the state in labour markets and processes, including current attempts to restructure the public sector. Second, by focusing on the new international environment, which gives us an opportunity to look both at accounts of globalisation and its effects, and more recent institutional theories of organisation.

The study of management rightly occupies a central place in the study of work organisations. But much of the writing has a narrow and technical conception of its nature and activities. Chapter 4 contrasts the extensive body of knowledge on management in mainstream literatures with radical perspectives and research that begins with analysis of management as control and as a labour process. A discussion of the extent to which management operates strategically is an essential part of this section. Traditionally, because organisations were conceived of as cohesive and unitary, the related theme of power was much neglected in mainstream writing. At best it was projected as a series of micro struggles, analogous to 'office politics'. Chapter 5 examines this literature and contrasts it to models of power drawn from radical theories. Of the latter, concepts drawn from Foucault and his emphasis on disciplinary power have become particularly influential in recent years, and such theorising is explained and criticised. Foucauldian perspectives have made their mark in analysis of gender and sexuality, but the issues go far wider than that. Organisations are gendered in many of their most everyday ways of operating. Though this is a theme that runs throughout the book, this chapter enables a closer look to be taken at this process of gendering organisational analysis.

Those who own and run organisations are continually looking for ways to design them more effectively, whether in terms of jobs, structures, 
communications systems or values. In the past, that mainstream debate has taken place within the framework of how to design bureaucracies differently. The emphasis now, from managerial and many radical theorists, is on postbureaucratic organisation, influenced by new environmental challenges and the Japanese model. Chapter 6 examines this supposed paradigm shift and looks in detail at research evidence in the key areas: firms and markets, the labour process, and corporate structures. In conclusion, a qualified defence of bureaucracy is made.

In the 1980s, corporate culture was perhaps the main talking point in managerial literature and was put forward as the key factor for business success. Chapter 7 looks critically at the merchandising of corporate cultures and examines whether it is an attempt to constitute a new form of 'organisation man'. Linking the debate to other contemporary issues such as the rise of Human Resource Management, the chapter examines the extent to which the management of culture can be successful in generating commitment and internalising values.

Part 2 begins by considering and defining the elements of what we term the 'subjective factor' in the study of organisations, which we see as manifested in the experiences of organisational participants and in the identities through which they transact with others in organisational environments. Our examination of these issues of subjectivity in Part 2 is initially viewed through psychological approaches which tend to focus mainly on behaviour as opposed to experience. The intention here is not to ignore the sociological and structural accounts of subjectivity available in the areas covered in Part 2. Rather, we begin in Chapter 8 by examining the deficiencies of behavioural approaches, along with some of the instruments and techniques, using the topics of perception, learning, attitudes, personality and motivation, in order to indicate how a closer articulation of structural and behavioural explanations can benefit the understanding of organisational subjectivity. In Chapter 9 we extend the theme taken in this chapter, examining how major theoretical areas within Organisational Behaviour have been incorporated into the agenda of regulation and control and the divisions of roles and practices within the discipline itself.

The study of what has come to be termed 'Organisational Behaviour' (OB) does in fact incorporate elements of the full range of academic disciplines and subject specialisms which might reasonably be expected to have something to say about people's lives in organisations and the influences on their activities. The major foundations of $\mathrm{OB}$ and the major inputs to the content of texts in the area are however informed mainly from the perspective of 'organisational psychology', which is in turn founded upon the subject divisions within social psychology. The treatment of subjectivity in organisational psychology does not typically develop upon the humanistic foundations of such issues within social psychology. It is generally subordinated to $\mathrm{OB}^{\prime}$ s agency in legitimating, developing and refining the social practices within which subjective identities 
are continuously recreated in images appropriate to the relations of social production. This theme is followed up in detail in Chapter 9 before moving on to examine explanation in the areas of groups, stress, communication and leadership. The aim again is to assess the nature and adequacy of the traditional agenda of mainstream study for an understanding of our experience of organisational life and how this shapes the construction of the identities through which we face it.

Chapter 10 attempts to integrate the themes of Chapters 8 and 9, first using an emphasis on motivation theories in order to investigate the mobilisation of commitment in modern work organisations. The focus on motivation and commitment is then used to explore the internalisation of self-controls and providing linkages to developments in technology and the field of Human Resource Management. In doing so, the later sections of this chapter tend to revisit many of the areas covered in Chapter 7, but viewing them from an $O B$ perspective. Readers will note some repetition of assertions of the relation of psychological knowledge to managerial ideology and practice. This overlap in the issues we investigate in Parts 1 and 2 is to some extent a recognition that since many readers will only dip into the book and not read the 'whole story' as intended, these points must perforce be made often. To those brave souls who traverse the whole text, we apologise in advance.

In Chapter 11 we return to consider in more detail the nature of identity and the contrasting approaches and resources a redefined agenda would need to focus on better to address issues of subjectivity. In particular, we address social relations such as those of domination, gender and ethnicity which are central features of work organisation. The issue of how subjectivity is experienced, structured and transformed within organisations is explored through the medium of the 'identity work' performed by organisational participants as a response to pressures on the identities they secure for themselves. These are viewed first from the context of the individual, then through a re-examination of groups, and lastly through the manner in which managerial identity work acts to structure the experience of everyone in organisations, regardless of hierarchical position.

Part 3 returns to the territory of the broader theorising of organisations, drawing on and linking to some of the substantive issues in previous chapters, as well as new themes such as agency and structure. Chapter 12 examines in detail the theoretical resources drawn on in mainstream and critical writing. The question of rationality is a central one in both traditions and through an examination of new, post-modern analyses of organisations, we explore the issues at stake and conclude that rationalisation remains a fundamental principle of organisational life and that rational enquiry, in a modified form, is an indispensable part of the theorising process. The chapter and book end with a wider discussion on the nature and uses of organisational knowledge. How do theorists using different paradigms speak to each other? How do managers use theory in practice? How can participants at work learn from 
Introduction xvii

past and present to create more democratic, as well as more efficient, organisations? 